\title{
Electronic Properties and Conformation Analysis of Phytochromobilins, Chromophore in Phytochrome
}

\author{
Cheol-Ju Kim and Dong Jin Yoo ${ }^{\dagger}$ \\ Deparment of Chemistry, Chonbuk National Lnwersity, Chonin 561-756, Korea. E-mail: cjkimachonbukackr \\ Department of Chemistry, Seonam Lniversitv, Namion 590-711, Korea \\ Recerved Ifarch 31, 2008
}

\begin{abstract}
Quantum-chemical investigation on the conformation analysis and electronic properties of phytochromobilins (PCBs). an open chain tetrapyrrole chromophore of phy tochrome are performed. The PCB chromophore have two stable forms. which occur photoisomerization by vișible light absorption. Structures for two stable forms. $\operatorname{Pr}$ and Pfr isomers were fully optimized by using semiempirical AMl. PM3 methods. ab initio HF/3-21G(d). and B3LYP/6-3 IG(d) methods. The potential energy curves with respect to the change of single torsion angle are obtained by using semiempirical methods. $a b$ initio HF. and DFT calculations. It is shown that the conformations of the isomers are compromised between the steric repulsion interaction and the degree of the conjugation. Electronic properties of the molecules were obtained by applying the optimized structures and geometries to the Zindo/S method. Absorption wavelengths are predicted by Zindo/S analysis. The wavelengths which are calculated from optimized geometries by $\mathrm{HF} / 3-2 \mathrm{IG}(\mathrm{d})$ and $\mathrm{B} 3 \mathrm{~L} \mathrm{YP} / 6-3 \mathrm{lG}(\mathrm{d})$ is reported. The absorption wavelength on the optimized geometries by B3L YP/6-3lG(d) is much longer than that by $\mathrm{HF} /$ 3-21G(d) level. The absorption wavelengths of Pfr form are longer than that of corresponding Pr form in the same torsion angle because of conjugation length difference. The absorption wavelengths of isomers with perpendicular linkage are shorter than those of planar linkage
\end{abstract}

Key Words : Conformation analysis. Potential energy curve, Phytochromobilins, Phytochrome, Electronic properties

\section{Introduction}

It is well-known that phytochrome is biliprotein photoreceptors of plants. fungi. and bacteria. Phytochromes allow these organisms to respond to environmental light conditions. ${ }^{1-3}$ Organisms can use light in two ways. The one is to use its energy to keep its cells functioning. the other is to use to transduce optical signals into some kind of biological response. Like rhodopsin in vertebrates. phytochrome in higher plants converts long wavelength light energy into cellular singnals inducing photomorphogenesis. The molecular basis of phytochrome action depends on the ability to convert between the stable isomers, the red light absorbing conformer. $\mathrm{Pr}$, and the far-red light absorbing conformer of phytochrome Pfr. This physisiological function is mediated via a light induced conversion of the parent state Pr form into the physiologically active state Pfr. $^{4-7}$ The primary reaction of the conversion consists of photoisomerization of the chromophore. which is followed by a series of thermally driven conformational changes of protein and chromophore

Even for the stable states. Pr and Pfr. the structure determination by X-ray crystallography and NMR spectroscopy is not possible due to the lake of crystals or due to protein size..$^{8-113}$ Other spectroscopic tecluniques have been employed to investigate the structure and conformation of the chromophore. One of the tecluniques is resonance Raman (RR) spectroscopy, which can characterize the vibrational band pattern of the chromophore. ${ }^{15.16}$ Some studies are showed that RR spectra have been obtained from the stable states. Pr and Pfr as well as from several intermediates formed during the reaction cycle.

After the assembly of the apoprotein with the chromophore. phytoclurome exists in a red light absorbing conformation (Pr). The absorption maximum of Pr form shows a peak around $660 \mathrm{~nm} .^{1.26 \mathrm{~T}}$ The cluromophore. phy tochromobilin (PCB) is covalently bound (formation of thioether bound a cystine residue) to the apoprotein. PCB is a open chain tetrapyrrolic chromophore (Fig. 1). Photoconversion is associated with very rapid isomerization around the $\mathrm{Cl5}$ C16 double bond followed by a series of slower conformatonal changes in the dark. PCB is changes its conformation via a $Z \rightarrow E$ isomerization, which brings protein into a different conformation, the far-red light absorbing form (Pfr). The absorption maximum of Pfr form shows a peak around $730 \mathrm{~nm}$ (Fig. 2.) ${ }^{3.6}$

Conformational studies of the chromophore have been performed by using $a b$ initio and semiempirical studies of oligopyrrolic compounds and tetrapyrrole backbone. ${ }^{11-1+}$ The oligopyrrolic compounds like pyrromethene and pyrromethenone are important as a source of information about structure and electronic properties of the cluromophore. The methenone molecule is adapted for model of non-lydrogen bonded part of the chromophore and the dipyrrolic pyrromethene is utilized as a model of hydrogen bond part of the chromophore. It was reported that $\mathrm{AMl}$ and the $a b$ initio and (HF/6-31G(d) and MP2/6-31G(d)) methods are reliable results for conformational analy sis. ${ }^{11.13}$ DHB (2.3-dihydrobilin- $119(21 \mathrm{H}, 24 \mathrm{H})$-dione) was studied as a model of the 
fully conjugated linear open chain tetrapyrroles. The geometries and energies of conformers were investigated with $\mathrm{AMl}$ and $\mathrm{HF} / 3-2 \mathrm{LG}$ (d) level and the results of the two methods was indicated that the geometries were investigated with a central sh-cis configuration are preferred to other conformations around the central methenine bridge. ${ }^{8.1+16}$ Conformation analysis in various metal-organic complex or oligomers in macromolecule are performed using $a b$ initio calculation. 30.31 .32

In this paper, PCB was chosen to investigate the effect of the conformations and electronic properties for conformational isomers, Pr. and Pfr. which are cluromophore of phytochrome. The molecular structure, conformational energies for the isomers formed by the rotation around the single bond between $\mathrm{C}$ and $\mathrm{D}$ ring. were calculated. To discuss the effect of the single bond rotation we will obtain the potential energy curves and first transition wavelengths for two stable conformers, Pr and Pfr of PCB. It was observed that the potential energy curves of PCBs calculated by AMI method are qualitatively similar to those found out by the $a b$ initio calculations. ${ }^{17.31}$ To obtain reliable information about conformation. we will report on a conformational analy sis of PCB using HF/3-21G(d) and B3LYP/6$3 \mathrm{IG}(\mathrm{d}) a b$ initio calculations. We selected the $\mathrm{HF} / 3-2 \mathrm{IG}(\mathrm{d})$ $a b$ initio method because of linitation of relatively large size of the molecules and the cost of calculations. To estimate the absorption maxima of UV spectra with respect to conformational change, the Zindo/S semiempirical method was employed. The first electronic transition energies were calculated from the Zindo/S method using the optimized geometry obtained at each computational level. ${ }^{21.24}$

\section{Methods and Computational Details}

The chromophore of phytochrome protein is covalently bounded to protein via a thioether linkage between a cystine residue and A-ring of the open chain tetrapyrrolic chromophore. To investigate the structure and electronic properties of the chromophore the molecule which thioether group of cysteine reside is capped into thiomethyl group are adopted as model of the open chain tetrapy'rrolic chromophore (Fig. 1) $\stackrel{1 \leq-27}{10}$

To obtain the optimized structures of PCBs. semiempirical
AMI, PM3 methods. $a$ b initio HF calculation with 3-2lG(d) basis set. and DFT calculation with B3LYP/6-31G(d) are employed ${ }^{23}$ Structures of Pr. and Pfr isomers of PCB were fully optimized by starting from initial structures of various torsion angles. respectively. One of the input structures were planar between A. B. C. and D pyrrole rings $\left(\psi_{1}=\psi_{2}=\psi_{3}=\right.$ $0 .\left(v^{3}\right)$. Another structures were the confonmations which pyrrole rings were almost perpendicular to vinylene group $\left(\psi_{1}=90^{\circ}, \psi_{2}=90^{\circ}\right.$. and $\left.\psi_{3}=90^{\circ}\right)$. The other structure was the conformation which phenyl groups were almost perpendicular to vinylene group $\left(\psi_{1}=90^{\circ}, \psi_{4}=90^{\circ}\right.$. and $\left.\psi_{3}=90^{\circ}\right)$. The parameters of the optimized structures were summarized in Table 1 . To investigate the stable confommational structures for the isomers, $a b$ initio calculations were carried out in the Gaussian 03 package. ${ }^{23}$ To display the potential energy curves for a variety of PCBs. the torsional angles $\left(\psi_{1}, \psi_{2}\right.$. and $\left.\psi_{3}\right)$ between the pyrrole groups and the vinyl unit were fixed at optimized torsion angles. The torsion angle, $\psi$, between the pyrrole rings and the vinyl unit varies by 10 degree as shown in Figure 1 and the torsion angle was fixed while the reminder of geometrical parameters of the isomer were fully optimized. The potential energy curves according to torsion angle. $\psi_{3}$ are obtained by by using semiempirical methods, $a b$ initio HF. and DFT calculations. ${ }^{13}$

Electronic properties of the isomers are obtained by applying the optimized structures and the selected geometries (maxima or minima) of potential curves to the Zindo/S method. ${ }^{21.23}$ The Zindo/S method including configuration integral as employed in the Gaussian 03 package was used to calculate the singlet-singlet electronic transition energies of the optimized conformers. To investigate the change of UV spectroscopic transitions with respect to the torsion angle, the optimized structures were selected. By using the results, the dependency of conjugation for the energy gaps is analyzed. The Zindo/S method has been shown to yield reliable electronic structures for a wide variety of conjugated polymers. including those with PPV derivatives. ${ }^{20}$

\section{Results and Discussion}

Equilibrium Structures of Pr and Pfr Isomers. For Pr and Pfr isomers, optimized structures of the lowest energy conformer of each is obtained by AMI method. PM3

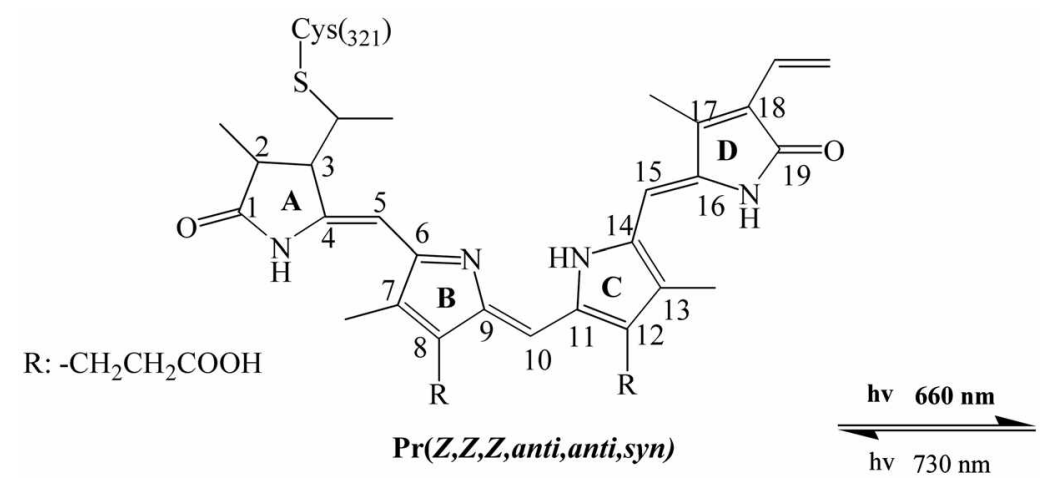

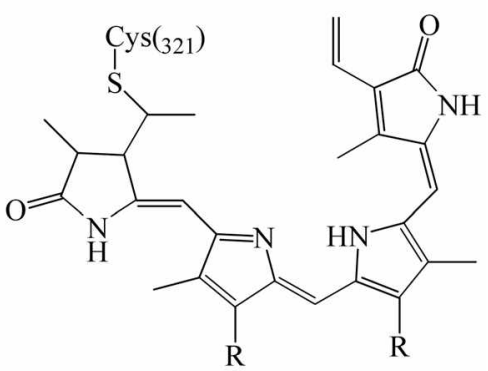

$\operatorname{Pfr}(Z, Z, E, a n t i, a n t i, a n t i)$

Figure 1. Structures of $\mathbf{P r}$ and $\mathbf{P f r}$ isomers. 
method, and HF/3-21G(d) method. The bond length and torsion angles of optimized structures are given in Table 1. The atomic numbering is indicated in Figure 1. The torsion angles are displayed that $\psi_{1}=\angle \mathrm{C} 4-\mathrm{C} 5-\mathrm{C} 6-\mathrm{N} 2 . \psi_{2}=\angle \mathrm{C} 9-$ $\mathrm{C} 10-\mathrm{Cll}-\mathrm{N} 3 . \psi_{3}=\angle \mathrm{N} 3-\mathrm{Cl} 4-\mathrm{Cl} 5-\mathrm{C} 16 . \psi_{4}=\angle \mathrm{Cl} 4-\mathrm{Cl} 15-$ $\mathrm{Cl}$ - $\mathrm{Cl} 7$, respectively.

For Pfr isomer, the AMI calculations are predicted that the vinyl unit is twisted by $\psi_{1}=125.0^{\circ}, \psi_{2}=-2.9^{\circ} . \psi_{3}=$ $55.7^{\circ}$. and $\psi_{4}=-175.6^{\circ}$, with respect to the pyrrole ring. respectively. The energy barrier over the planar conformation is very small as shown in Table 2. The $a b$ initio HF calculations for Pfr, support the AMl results. producing a quit flat potential energy curve up to the torsion angles of $\psi_{1}$ $=131.8^{\circ} . \psi_{2}=3.2^{\circ} \cdot \psi_{3}=-43.7^{\circ}$, and $\psi_{4}=172.0^{\circ}$. In optimized geometry obtained from DFT calculation. the torsion angles are given by $\psi_{1}=1+9.6^{\circ}, \psi_{2}=-1.0^{\circ} . \psi_{3}=-26.5^{\circ}$. and $\psi_{+}=167.8^{\circ}$. The pyrrole rings $\mathrm{A}$ is twisted to the pyrrole ring B. the pyrrole ring $C$ is planar with respect to the pyrrole ring $\mathrm{B}$. the pyrrole ring $\mathrm{D}$ is twisted to the pyrrole ring $\mathrm{C}$. The torsion angles of Pfr computed at PM3, are close to the AMl results. The PM3 equilibrium structure of Pfr isomer are produced a quit planar, the torsion angles are, $\psi_{1}=93.9^{\circ}$. $\psi_{2}=1.6^{\circ} . \psi_{3}=98.1^{\circ}$, and $\psi_{4}=-176.8^{\circ}$. The pyrrole rings $\mathrm{A}$ is perpendicular to the pyrrole ring $\mathrm{B}$. the pyrrole ring $\mathrm{C}$ is planar with respect to the pyrrole ring $B$. the pyrrole ring $D$ is twisted to the pyrrole ring $\mathrm{C}^{11}$

In the case of $\mathrm{Pr}$ isomer. the torsion angles are considerably reasonable. the AMI calculations are predicted that the vinyl unit is twisted by $\psi_{1}=125.0^{\circ} . \psi_{z}=-2.0^{\circ} . \psi_{3}=$ $32.5^{\circ}$. and $\psi_{4}=4.0^{\circ}$. respectively. The $a b$ initio calculations for Pr, support the AMI results. producing a quit flat potential energy curve up to the torsion angles of $\psi_{1}=$ $136.3^{\circ}, \psi_{2}=6.1^{\circ}, \psi_{3}=-12.0^{\circ}$. and $\psi_{4}=-3.2^{\circ}$. The conformation of $\mathrm{Pr}$ isomer is predicted that the pyrrole rings $\mathrm{A}$ is twisted to the pyrrole ring $B$. the pyrrole ring $C$ is planar with respect to the pyrrole ring $B$, and the pyrrole ring $D$ is twisted to the pyrrole ring $\mathrm{C}$. The torsion angles of $\mathbf{P r}$ computed at PM3. are different from the AMl results. The PM3 equilibrium structure of $\mathbf{P r}$ isomer are produced a quit planar, the torsion angles are, $\psi_{3}=73.8^{\circ}, \psi_{2}=-22.4^{\circ}, \psi_{3}=$ $-1.2^{\circ}$, and $\psi_{4}=-3.7^{\circ}$. In optimized geometry obtained from DFT calculation. the torsion angles are given by $\psi_{1}=152.8^{\circ}$. $\psi_{2}=-1.65^{\circ} . \psi_{3}=11.5^{\circ}$. and $\psi_{4}=3.8^{\circ}$. The pyrrole rings $\mathrm{A}$ is perpendicular to the pyrrole ring $B$. the pyrrole ring $C$ is planar with respect to the pyrrole ring $B$. the pyrrole ring $D$ is twisted to the pyrrole ring $\mathrm{C}$.

Gorb et al. reported conformational analysis results for dipyrrolic compound. pyrromethenone by using AMI, PM3. $\mathrm{HF} / 3-2 \mathrm{IG}(\mathrm{d})$. and $\mathrm{B} 3 \mathrm{LYP} / 6-3 \mathrm{IG}(\mathrm{d})$ methods. ${ }^{11.13}$ The results for AMl method were in qualitative are agreement with $\mathrm{HF}$ method. The torsion angles of $Z, s, n$ and $Z$,ant $i$ conformers were $150^{\circ}-159^{\circ}, 30^{\circ}$, respectively. The torsion angles of $E, s, n$ and $E, a n t i$ conformers were $145^{\circ}-147^{\circ}, 36^{\circ}-42^{\circ}$, respectively.

For $\mathbf{P r}$ and $\mathbf{P f r}$ isomers, the single bond lengths in conjugated backbone for $a b$ initio HF calculation are longer than that for AMl calculation. However. the double bond length of the group in $a b$ initio calculation is shorter than the length from AMI result. Finally, in $a b$ initio calculation the bond alternations are $0.151-0.160 \AA$ and in the case of AMl result the alternations are $0.108-0.113 \AA$. The differences for the bond alternation with respect to calculation methods affect in the obtained optical properties for $\mathbf{P r}$ and $\mathbf{P f r}$ isomers. The effect of the bond alternation in optical properties will be discussed later.

Conformational Analysis of Pr and Pfr Isomer: Recently, conformational analysis of organic molecules as the model for PCBs have been carried out from $a b$ initio calculations

Table 1. Optimized geometric parameters of Pr and Pfr isomers. Bond lengths (Angstrom) and torsion angles (degree) ${ }^{a}$

\begin{tabular}{|c|c|c|c|c|c|c|c|c|}
\hline \multirow{2}{*}{ Parameters } & \multicolumn{4}{|c|}{ Pfr } & \multicolumn{4}{|c|}{ Pr } \\
\hline & $\mathrm{AMl}$ & PM 3 & $\mathrm{HF}^{b}$ & $\mathrm{DFT}^{\circ}$ & $\mathrm{AMl}$ & PM3 & HF & DFT \\
\hline \multicolumn{9}{|c|}{ Bond length $(\AA)$} \\
\hline $\mathrm{C}_{4}-\mathrm{C}_{s}$ & 1.349 & 1.342 & 1.322 & 1.352 & 1.340 & 1.342 & 1.323 & 1.323 \\
\hline $\mathrm{C}_{4}-\mathrm{C}_{0}$ & 1.451 & 1.456 & 1.466 & 1.456 & 1.451 & 1.453 & 1.459 & 1.452 \\
\hline $\mathrm{C}_{6}-\mathrm{N}_{2}$ & 1.329 & 1.326 & 1.295 & 1.332 & 1.322 & 1.325 & 1.296 & 1.334 \\
\hline $\mathrm{N}_{2}-\mathrm{C}_{9}$ & 1.433 & 1.445 & 1.417 & 1.390 & 1.446 & 1.418 & 1.417 & 1.391 \\
\hline $\mathrm{C}_{4}-\mathrm{C}_{11}$ & 1.355 & 1.349 & 1.342 & 1.393 & 1.320 & 1.350 & 1.343 & 1.384 \\
\hline $\mathrm{C}_{10}-\mathrm{C}_{11}$ & 1.430 & 1.429 & 1.424 & 1.414 & 1.430 & 1.432 & 1.431 & 1.418 \\
\hline $\mathrm{C}_{11}-\mathrm{N}_{\mathfrak{s}}$ & 1.388 & 1.392 & 1.370 & 1.421 & 1.395 & 1.398 & 1.364 & 1.372 \\
\hline $\mathrm{N}_{3}-\mathrm{C}_{14}$ & 1.412 & 1.450 & 1.354 & 1.404 & 1.389 & 1.392 & 1.354 & 1.364 \\
\hline $\mathrm{C}_{1.4}-\mathrm{C}_{15}$ & 1.432 & 1.435 & 1.456 & 1.422 & 1.425 & 1.436 & 1.445 & 1.429 \\
\hline $\mathrm{C}_{1:-\mathrm{C}_{10}}$ & 1.352 & 1.344 & 1.330 & 1.369 & 1.345 & 1.347 & 1.332 & 1.369 \\
\hline \multicolumn{9}{|c|}{ Iorsion angles } \\
\hline$\psi_{1}$ & 125.0 & 93.9 & 131.8 & 149.6 & 125.0 & 73.8 & 136.3 & 152.8 \\
\hline$\psi 2$ & -2.9 & 1.6 & 3.2 & -1.0 & -2.0 & -22.4 & 6.1 & -1.6 \\
\hline$\psi_{s}$ & 55.7 & 98.1 & -43.7 & -26.5 & 32.5 & -1.2 & -12.0 & 11.5 \\
\hline$\psi_{1}$ & -175.6 & -176.8 & 172.0 & 167.8 & 4.0 & -3.7 & -3.2 & 3.8 \\
\hline
\end{tabular}

"Torsion angles: $\psi_{1}=\angle \mathrm{C}_{4}-\mathrm{C}_{5}-\mathrm{C}_{6}-\mathrm{N}_{2}: \psi_{2}=\angle \mathrm{C}_{4}-\mathrm{C}_{10}-\mathrm{C}_{11}-\mathrm{N}_{2}: \psi_{3}=\angle \mathrm{N}_{2}-\mathrm{C}_{14}-\mathrm{C}_{15}-\mathrm{C}_{16}: \psi_{4}=\angle \mathrm{C}_{14}-\mathrm{C}_{15}-\mathrm{C}_{16}-\mathrm{N}_{4}$. Optimized structure from $\mathrm{HF}$ calculation with $3-2 \mathrm{IG}(\mathrm{d})$ basis set. ${ }^{\circ}$ Optimized structure from $\mathrm{DFT}$ calculation with $6-3 \mathrm{IG}(\mathrm{d})$ basis set. 
using a various of basis sets. ${ }^{11,13}$ For the methoxy-substituted thiophene oligomers. Dicesare $e t$ al. reported that the HF/3$2 \mathrm{IG}(\mathrm{d})$ and $\mathrm{HF} / 6-3 \mathrm{IG}(\mathrm{d})$ basis sets give identical potential energy surface with similar energy barriers and minima. ${ }^{20}$ We have used the HF/3-21G(d) method as the more elaborated calculation in this paper to have resonable calculation times and because this basis set gives similar result in comparison with more elaborated basis sets. Potential energy curves of the Pr and Pfr isomers of PCB molecule are obtained by $a b$ initio $\mathrm{HF} / 3-21 \mathrm{G}(\mathrm{d})$ and $\mathrm{DFT} / 6-31 \mathrm{G}(\mathrm{d})$ as well as senientirical calculation as shown in Figures 2 and 3. The energies and torsion angles of the minima and maxima of each molecule as obtained by semiempirical. $\mathrm{HF} /$ $3-21 \mathrm{G}(\mathrm{d})$, and $\mathrm{B} 3 \mathrm{LYP} / 6-31 \mathrm{G}(\mathrm{d})$ methods are displayed in Table 2 .

In optimized structures, the torsion angles between pyrrole ring (B) and vinylene group adjoining pyrrole ring $(A)$ are around $120^{\circ}$. but not planar. The $p$-orbitals of B-ring are perpendicular to the $p$-orbitals of vinylene carbons. so that the resonance structure between B-ring and vinylene carbons may not expected. The optimized structures of $\mathbf{P f r}$ and $\mathbf{P r}$ isomers are given torsion angle $\left(\psi_{1}\right)$ of $131.8^{\circ}$ and $136.3^{\circ}$ by using $\mathrm{HF} / 3-2 \mathrm{lG}(\mathrm{d})$ basis set, respectively. The torsion angles between pyrrole ring $(\mathrm{C})$ and vinylene group adjoining pyrrole ring $(\mathrm{B})$ are around $0^{\circ}$. The $p$-orbitals of B-ring are planar to the $p$-orbitals of vinylene carbons. so that the resonance structure between B-ring and vinylene carbons may expected. The optimized structures of Pfr and Pr isomers are given torsion angle $\left(\psi_{z}\right)$ of $3.2^{\circ}$ and $6.1^{\circ}$ by using $3-21 \mathrm{G}$ (d) basis set. respectively. The torsion angles between pyrrole ring $(\mathrm{C})$ and vinylene group adjoining pyrrole ring (D) are twisted. The $p$-orbitals of C-ring are planar to the $p$ orbitals of vinylencarbons, so that the resonance structure between $\mathrm{C}$-ring and vinylene carbons may expected. The optimized structures of Pfr and Pr isomers are givent torsion angle $\left(\psi_{3}\right)$ of $-43.7^{\circ}$ and $-12.0^{\circ}$ by using $3-21 \mathrm{G}(\mathrm{d})$ basis set. respectively. For $\mathbf{P f r}$ and $\mathbf{P r}$ isomers. sn conformers are more favorable than the anti confommers. Sin conformers can not exist due to steric hinderance between methyl group in $\mathrm{C}$ pyrrole ring and $\mathrm{N}-\mathrm{H}$ group in $\mathrm{D}$ ring. ${ }^{11.13,31\}}$ However conformers can be experienced steric hinderance between methyl group in $\mathrm{C}$ pyrrole ring and methyl group in $\mathrm{D}$ ring. The energy difference between sin conformers and twisted conformers is small. In partial. the energy for syn conformers of $\mathbf{P r}$ isomer almost equal to twisted conformer. The $\mathrm{HF} / 3-21 \mathrm{G}$ (d) results give that the barrier between sinn conformer and twisted conformer in $\mathbf{P f r}$ and $\mathbf{P r}$ isomers are 3.77 and $0.98 \mathrm{kcal} / \mathrm{mol}$. respectively.

For the confonmation analysis of the Pfr and Pr isomers. the twisted conformers are more stable than the coplanar structure because of the steric repulsion. The potential energy curves of $\mathbf{P r}$ are displayed in Figure 2. It is clear that the $\mathrm{HF} / 3-21 \mathrm{G}(\mathrm{d})$ result gives higher rotational energy barrier than AMl and PM3 results. However. the potential energy surfaces obtained from semiempirical PM3 method is not considerably realistic ${ }^{14.15}$ The rotational energy barrier from $\mathrm{B} 3 \mathrm{LYP} / 6-31 \mathrm{G}$ (d) result is higher than $\mathrm{HF} / 3-2 \mathrm{IG}$ (d) result.
The minimum were coplanar conformation where we expect some steric hinderance. even though the potential maximum is similar to that of the AMI method. The potential energy curves for $\mathbf{P r}$ isomer are very similar with respect to each calculation method.

$A b$ initio calculations performed at the $\mathrm{HF} / 3-21 \mathrm{G}$ (d) level show that the most stable conformations of Pr isomer corresponds to twist structures with torsion angles around $-12.0^{\circ}$ as shown in Figure 2. From the result for HF method the twisted conformers of $\mathbf{P r}$ isomer are found to be more stable than the anti conformation by 11.68 and stable than the $s \mathrm{~m}$ confomation by $1.00 \mathrm{kcal} / \mathrm{mol}$, respectively, as shown in Table 2. The perpendicular conformer is higher barrier than twist conformer by $8.72 \mathrm{kcal} / \mathrm{mol}$. In the case of $\mathrm{B} 3 \mathrm{LYP} / 6$ $3 \mathrm{lG}(\mathrm{d})$, the twisted confomers of $\mathrm{Pr}$ isomer are found to be more stable than the anti confomation by 7.23 . and stable than the $8 \mathrm{~g} n$ conformation by $0.43 \mathrm{kcal} / \mathrm{mol}$, respectively, The perpendicular conformer is higher barrier than twist conformer by $7.48 \mathrm{kcal} / \mathrm{mol}$. Two factors are involved in the

\section{Energy profiles for Pr Isomer}

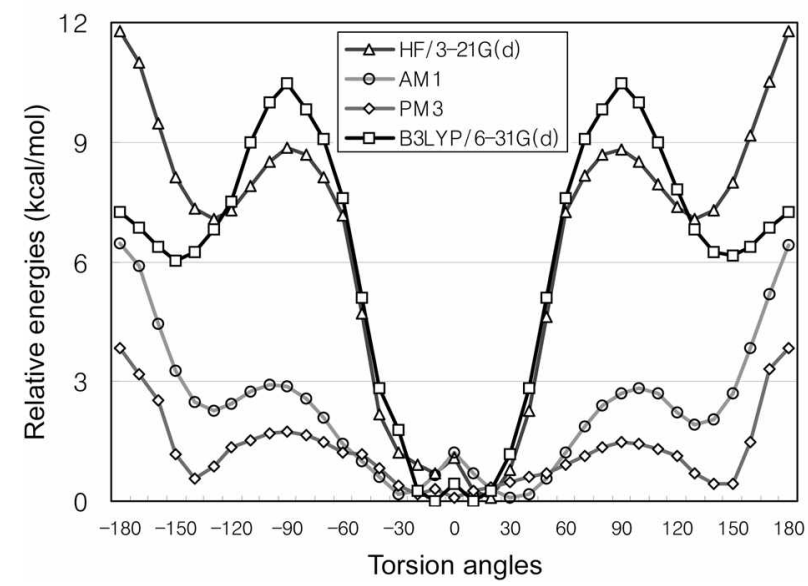

Figure 2. $A$ b initio $\mathrm{HF} / 3-21 \mathrm{G}(\mathrm{d})$, B3LYP/6-31G(d), PM3, and AMl potential energy curves for $\mathrm{Pr}$ isomer. Torsion angles of pyrrole groups ( $\mathrm{C}-\mathrm{D}$ rings) are varied with $\psi 3$.

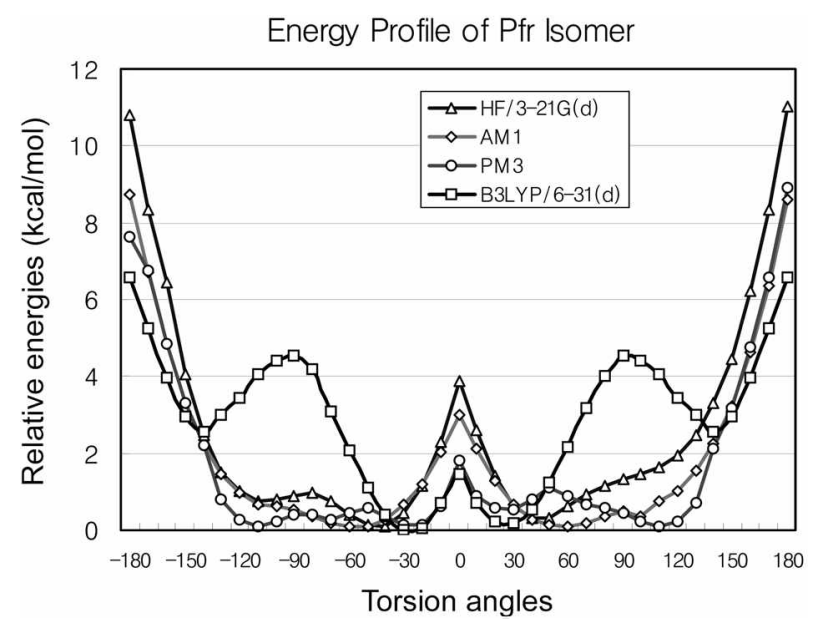

Figure 3. Ab initio $3-2 \mathrm{lG}(\mathrm{d}), \mathrm{B} 3 \mathrm{LYP} / 6-3 \mathrm{lG}(\mathrm{d})$, PM 3 , and $\mathrm{AMl}$ potential energy curves for Pfr isomer. 
Table 2. Relative energles ( $\Delta E, \mathrm{kcal} / \mathrm{mnol}$ ) and torsion angles (degree) at the C-D ring for minimum energy and transition structures of $\mathbf{P r}$ and $\mathbf{P f r}$ isomers

\begin{tabular}{|c|c|c|c|c|c|}
\hline \multirow[b]{2}{*}{ Structures } & & \multicolumn{4}{|c|}{ Methods } \\
\hline & & AMl & PM3 & $\begin{array}{c}\mathrm{HF} / \\
3-2 \mathrm{lg}(\mathrm{d})\end{array}$ & $\begin{array}{c}\text { BLYP/ } \\
6-\hat{3} \mathrm{lG}(\mathrm{d})\end{array}$ \\
\hline \multirow[t]{2}{*}{$\operatorname{Pfr}(\text { twist } I)^{\sigma}$} & $\Delta E$ & 0.0 & 0.0 & 0.0 & 0.0 \\
\hline & $\psi_{3}$ & 55.7 & -20.0 & -43.7 & -26.5 \\
\hline \multirow[t]{2}{*}{$\operatorname{Pfr}(\text { twist } I)^{b}$} & $\Delta E$ & - & 0.0 & - & 2.54 \\
\hline & $\psi_{3}$ & - & 98.1 & - & 150.0 \\
\hline Pfr(syn) & $\Delta E$ & 2.91 & 1.71 & 3.76 & 1.44 \\
\hline $\operatorname{Pfr}(\text { perp })^{\gamma}$ & $\Delta E$ & 0.39 & 0.34 & 1.21 & 4.55 \\
\hline $\operatorname{Pfr}(a n t i)^{p}$ & $\Delta E$ & 8.49 & 8.79 & 10.86 & 6.55 \\
\hline \multirow[t]{2}{*}{$\operatorname{Pr}($ twist $I)$} & $\Delta E$ & 0.0 & 00 & 00 & 00 \\
\hline & $\psi_{3}$ & 325 & -1.2 & -120 & 115 \\
\hline \multirow[t]{2}{*}{$\operatorname{Pr}($ twist $I I)$} & $\Delta E$ & 179 & 0.35 & 700 & 602 \\
\hline & $\psi_{3}$ & 1300 & 140.0 & 1300 & 1500 \\
\hline $\operatorname{Pr}(s y n)$ & $\Delta E$ & 1.12 & 00 & 100 & $0.4 \hat{3}$ \\
\hline $\operatorname{Pr}($ perp $)$ & $\Delta E$ & 136 & 136 & 870 & 10) 46 \\
\hline $\operatorname{Pr}(a n t i)$ & $\Delta E$ & 634 & 3.73 & 11.65 & 7,21 \\
\hline
\end{tabular}

twist $I$ form is the most stable conformer and $\psi_{3}=\angle \mathrm{N}_{3}-\mathrm{C}_{14-}-\mathrm{C}_{15}-\mathrm{C}_{16}$. "twist $I I$ fon is the local minimum confonner between perp and anti forms. 'syn form is the conformer that the torsion angle, $\psi_{3}$ is $0.0^{\circ}$. "perpendicular form is the conformer that the torsion angle. $\psi_{2}$ is $90.0^{\circ}$. "anti form is the conformer that the torsion angle. $\psi_{s}$ is $180.0^{\circ}$.

description for the molecular conformation of the $\mathbf{P r}$ isomer. The steric hinderance between the hydrogen of pyrrole group and that of vinyl group. which favors twisted conformations and the $\pi$-electron conjugation along the molecular frame, which favors the planarity of the molecule. The equilibrium structures of Pr isomer can be considered as a compromise between these two factors. However the energy barrier between the twisted confonmer and planar conformer is so small. ${ }^{11.13 .14}$

The potential energy curve of Pfr are displayed in Figure 3. At the HF/3-2l(d) level the most stable conformations of Pfr isomer corresponds to twist structures with torsion angles around $-43.7^{\circ}$ as shown in Figure 3. From the result for HF method the twisted confomers of Pfr isomer are found to be more stable than the anti conformation by 10.90 . and stable than the sin conformation by $1.22 \mathrm{kcal} / \mathrm{mol}$. respectively, as shown in Table 2 . The perpendicular conformer is higher barrier than twist conformer by $3.77 \mathrm{kcal} /$ mol. In the case of B3LYP/6-31G(d), the twisted confonmers of $\mathrm{Pr}$ isomer are found to be more stable than the anti conformation by 6.56 . and stable than the sin conformation by $1.45 \mathrm{kcal} / \mathrm{mol}$. respectively. The perpendicular conformer is higher barrier than twist confomer by $4.56 \mathrm{kcal} / \mathrm{mol}$.

The twisted conformers of $\mathbf{P f r}$ and $\mathbf{P r}$ isomers in ab initio $\mathrm{HF} / 3-2 \mathrm{lG}(\mathrm{d})$ calculation are found to be far more stable than the perpendicular structure by $1.22 .8 .72 \mathrm{kcal} / \mathrm{mol}$. respectively. The rotational energy' barriers between the twisted and the perpendicular conformer are much higher than those between twisted and planar conformer. The perpendicular conformers are unfavorable energetically because $\pi$-electron conjugation in the molecular frame is interrupted. The

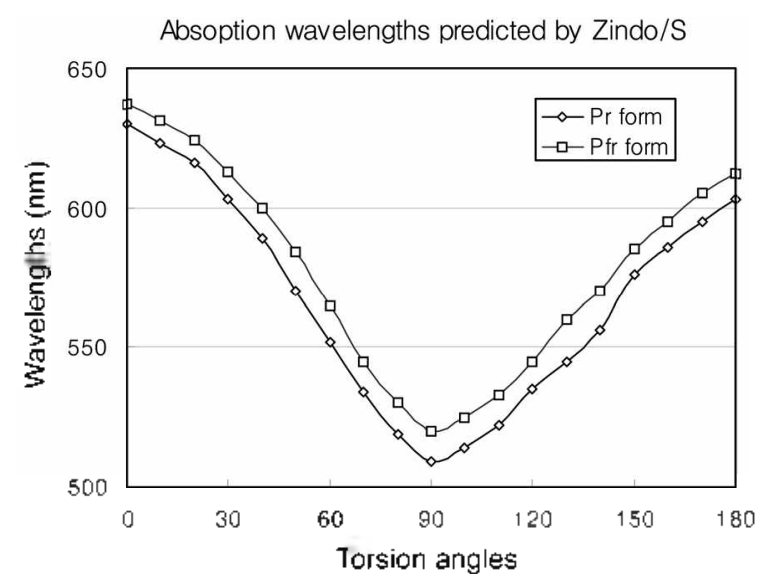

Figure 4. First singlet-singlet electronic transition wavelengths (nm) of Pr and Pfr isomers predicted by Zindo/S calculation for optimized geometries at B SLYP/6-31G(d).

barriers from AMI calculation show considerably smaller than the results by $a b$ initio calculations. According to the conformation analysis of Pfr, the sy conformer which Cring is perpendicular to D-ring are more stable than the coplanar or twist structure because of the steric repulsion of substituents. As shown in the conformational analysis of Pfr, the HF/3-2lG(d). B3LYP/6-3IG(d), and AMl methods give similar potential energy surfaces each other.

Electronic Properties of $\mathrm{Pr}$ and Pfr Isomer: The first electronic transition energies were calculated from Zindo/S semiempirical method using the optimized geometry obtained at each calculation levels. For $\mathbf{P r}$ and $\mathbf{P f r}$ isomers. the transition wavelengths in optimized geometries are displayed in Figure 4. The transition energies are absolutely depend on the torsion angle between $C$ and D-ring rings. The predicted $\lambda_{\text {max }}$ values for optimized Pfr structures are more red shifted than that for the corresponding $\mathrm{Pr}$ isomer at each torsion angle. The red slift calculated is attributed to the conjugation length of pyrrolic chain and steric hinderance of substituents.

The electronic transition energies from $\mathrm{Zindo} / \mathrm{S}$ calculation strongly depend on the optimized geometric parameters in the calculations for the same torsional angle. In fact. transition energies for optimized structures from semiempirical AMl and PM3 methods are smaller than those for geometries optinized at $a b$ initio calculation. Each geometrical parameter may influence the transition energies obtained by Zindo/S calculation. ${ }^{2 n .12}$ For methoxy-substituted bithiophene system. DiCesare $e t$ al. reported that the structure calculated from $a b$ initio method gives the methoxy groups as twisted relatively to the molecular frame. whereas in the structure from semiempirical methods methoxy groups placed in coplanar with the rest of the molecule $^{28}$

However, the transition energies for $\mathbf{P r}$ isomer are displayed the same tendency as $\mathbf{P f r}$ isomer in our calculation. To find another geometrical factor for the transition energy: we have investigated the effect of the bond altemation of vinylene linker group for each calculation. It was mentioned 
Table 3. Zindo/S results for electronic transition wavelengths(1n11) of Pr and Pfr isomers for optimized structures by using $a b$ intitio $\mathrm{HF} / 3-21 \mathrm{G}(\mathrm{d})$ and $\mathrm{AMl}$ methods

\begin{tabular}{llcccc}
\hline Isomers & Method & syn & nvist $^{\prime}$ & perpend $^{b}$ & anti \\
\hline Pfr & HF/3-21G(d) & 536 & 528 & 449 & 506 \\
& B3LYP/6-31G(d) & 630 & 601 & 529 & 607 \\
\hline Pr & HF/3-21G(d) & 527 & 495 & 452 & 506 \\
& B3LYP/6-31G(d) & 639 & 631 & 509 & 603 \\
\hline
\end{tabular}

"The transition wavelengths at angles given in Table 2. "The transition wavelengths at angle, $\psi_{2}=90^{\circ}$.

in equilibrium geometries that the bond alternation of the structure optimized at the $\mathrm{HF} / 3-21 \mathrm{G}$ (d) method gives larger than that of the structure from semiempirical methods. It is indicated that the result of AMI calculation give more conjugate geometry than $a b$ initio calculation.

For each calculation method used to obtain optimized geometries. the absorption wavelength is considerably different. However. the wavelength decreases as the molecule becomes more twisted. This tendency is well known and is due to decrease in the overlap between $\mathrm{p}_{\llcorner}$orbitals of carbon atoms in the phenyl ring and vinyl group as the torsional angle increase. This induces to a reduction in the electronic conjugation length and an increase in the electronic transition energy. ${ }^{20}$

$$
\lambda_{\text {max }}(\text { Predict })=\lambda_{i_{1}}-\Delta \lambda / 2\left(\sin \phi+\sin ^{2} \phi\right) .
$$

where $\lambda_{0}$ is the absorption wavelength of optinized geometry at torsion angle. $\phi=0^{\circ}$. and $\Delta \lambda$ is the difference between the absorption wavelengths at $90^{\circ}$ and $0^{\circ}$.

The absorption wavelengths at the potential minima (or maxima) for $\mathbf{P r}$ and $\mathbf{P f r}$ isoners are shown in Table 3. The absorption wavelengths are calculated at optimized geometry from $\mathrm{HF} / 3-21 \mathrm{G}(\mathrm{d})$ and $\mathrm{B} 3 \mathrm{LYP} / 6-3 \mathrm{lG}(\mathrm{d})$ level. The wavelengths from $\mathrm{B} 3 \mathrm{LYP} / 6-31 \mathrm{G}(\mathrm{d})$ geonetries are larger than the values from $\mathrm{HF} / 3-21 \mathrm{G}(\mathrm{d})$. However. it is shown that electronic properties of the isomers strongly depend on the planarity of py'rrole groups and vinylene groups.

The planarity between vinylene and phenyl group is affected to produce the changes in electronic properties. $4,6,7$ HOMO-LUMO gaps are small by increasing the planarity. At a torsion angle of $90^{\circ}$, the energy gaps of the conjugated systems increase to maxintun due to the reduced $\pi$ overlap between the phenyl ring and the vinylene unit. Since the interaction between the phenyl rings and the vinylene unit is antibonding in HOMO and bonding in the LUMO. the reduction of $\pi$ overlap stabilizes the HOMO level, but destabilizes the LUMO level. The degree of the stabilization of the HOMO energy level is smaller in energy than the destabilization of the LUMO energy level ${ }^{6.7}$ For Pr and Pfr isomers the wavelength, $\lambda_{\text {max }}$ values according to change of conformations are predicted as shown in as shown in Figure 4

In summary, the potential energy curves in $\mathbf{P r}$ and $\mathbf{P f r}$ isomers are different shapes each other in building block of PCB molecule. including the vinyl groups and pyrrole groups. However. the curves for each isomer in according to calculation method are similar shape. It is shown that the steric repulsion interactions between pyrrole ring and vinyl group are subjected to similar type. For the fully conjugate molecules. $\lambda_{\text {max }}$ values according to change of conformations will changes because of the steric repulsion interaction and the difference of $\pi$-conjugation.

\section{Conclusion}

Structures of Pr and Pfr isomers of PCB chromophore of phytochrome were optimized and conformational analysis for the isomers are performed in semiemprirical and $a b$ initio method. As shown in Figure 2 and 3, the potential energy curves of two isomers are shown symmetric shape about planar confonmation. In $\mathrm{Pr}$ isomer, semiemprirical result are different from $a b$ initio methods. The potential energy surfaces predicted by AMI and ab initio methods are quite shallow around the planar conformations $\left(-40^{\circ} \sim 40^{\circ}\right)$. The energy barrier of perpendicular conformers are less than $3.0 \mathrm{kcal}$. However, The HF and DFT results for $\mathbf{P r}$ isomer are shown that the energy barrier of perpendicular conformers come up to 8.72 and $10.48 \mathrm{kcal} / \mathrm{mol}$, respectively. For potential energy curves of $\mathbf{P f r}$ isomer, DFT result are different from semiempirical and HF results. Semiempirical and HF result the energy barrier of perpendicular conformers are not exist. In DFT calculation the energy barrier of perpendicular confommers are about $4.56 \mathrm{kcal} / \mathrm{mol}$.

This fact results from the compromise between two factors, a repulsion interaction and a $\pi$-conjugation effect. The repulsion interaction is mainly attributed to the short distances between hydrogen atoms on the pyrrole and the vinylene unit for PCB. However. in the case of Pfr isomer, there are repulsion not only between methyl group in C-ring and metlyyl group in D-ring. but also between hydrogen atoms on the C-pyrrole ring and methyl group in D-ring. In the planar confonmer of $\mathbf{P f r}$ isomer, the distances are too short compared to the sum of the van der Waals radii. The $\pi$ conjugation effect results from the fact that the large overlap between the $\pi$ orbitals of $C$ atoms linking between the pyrrole and the vinylene units gives stable confonnation. For Pr isomer, there can not be repulsion between methyl group in C-ring and methyl group in D-ring. and between hydrogen atoms on the C-py'rrole ring and methyl group in D-ring. In the planar confonmer of $\mathrm{Pr}$ isomer. it is stabilized by $\pi$ conjugation effect. Although the small rotation barrier are experienced in $\mathbf{P r}$ isomer the perpendicular confonmer of $\mathbf{P r}$ isomer is more stable than Pfr isomer.

The electronic transition energies from Zindo/S calculation strongly depend on the optimized geometric parameters in the calculations for the same torsional angle. In fact. transition energies for optimized structures from semiempirical AM1 and PM3 methods are smaller than those for optimized geometries from $a b$ initio HF and DFT calculation. Although the predicted UV absorption wavelengths are not quantitatively equal to experimental data. the results are similar qualitatively. It should be considered that solvent effect and 
the interactions between chromophore and phytochrome protein residues in order to explain the exact result.

Acknowledgments. This work was supported by grant (Grant No. R05-2003-000-12034-0) from the Basic Research Program of the Korea Science and Engineering Foundation. The author is grateful to the Computer Center of Chonbuk National University for the use of their computing facilities.

\section{References}

1. (a) Eichenberg. K:: Baeurle. I.: Paulo. N.: Sharrock. R. A: Ruediger. W.: Schaefer. E. FEBS Letts. 2000. 470. 107. (b) Quail. P. H. Amu. Rev Genet. 1995. 25. 389.

2. (a) Kneip. C.: Moslev. D.: Hildebrandt. P. Gartner. W: Braslavsky. S. E.: Schaffiner K. FEBS Letts. 1997, 41, 23. (b) Kneip. C.: Schlamann. W: Hildebrandt. P.: Braslarski. S. E.: Schaffiner. K. FEBS Letts. 2000. 482. 256. (c) Matysik. J.: Hildebrandt. P: Schlamann. W: Braslavsky. S. E.: Schafther. K. Biochemism 1995. 34. 10497.

3. Schmidt P: Westphal, U. H: Worm. K.: Braslavsky, S. E: Gartner, W.: Schaffiner, K. J. Photochem. Photobiol. B: Biology: $1996,34,73$.

4. Wagner. J. R.: Brunzelle. J. S.: Forest. K. T:: Vierstra. R. D. Nattire 2005 - 138.325

5. Foerstendorf. H.: Mummert. E.: Schaefer. E.: Scheer. H.: Siebert. F. Biochemishy 1996.35, 10793.

6. Kneip, C.: Hildebrandt. P: Schlamann. W: Braslavsky, S. E.: Mark F.: Schaffiner. K. Biochemishv 1999, 38. 15185.

7. Andel F: Lagarias. J. C.: Mathies, R. A. Biochemishy 1996. 35. 15997.

8. Borg. O. A.: Durbeej. B. J. Phvs. Chent. B 2007. H11. 11554.

9. von Ther. J. J.: Mackeen. M.: Kuprov. I.: Dwek. R. A.: Wormald. M. R. Bioplys. J. 2006, 91, 1811.

10. Evans, K.: Grossmann. J. G.; Fordham-Sketton. A.; Papiz, M. Z.J. Hol. Biol. 2006. $3+6.655$

11. (a) Gorb. L.: Korkin. A.: Leszczynski. J. J. Mfol Stmact. Theochem 1998. 45t. 217. (b) Gorb. L.: Korkin. A.: Leszczynski. J.: Varneck. A.: Mark. F. J. A fol Strict. (Theocheni) 1998. 125.137.

12. Marai C. N. I. Chass. A. A. Doust A. B.: Scholes. G. D. J. Mol. Struct. (Theochem) 2004, 680. 219.

13. Korkin, A: Merk. F; Schaffner, K.; Gorb. L. J. Mol. Struc. (Theochem) 1996. 388.121

14. Zahedi. M.: Shaabani. A.: Safari. N. J. hol Sirtct. Theochem 1998. 452.125

15. Magdo, H.: Nemeth. K: Mark. F: Hidebrandt P.: Schaffner. K. J. Phys. Chem. A 1999, 103. 289

16. Mroginsky. M. A.: Murgida. D. H. Hidebrandt. P. Acc. Chem. Res. $2007 .+10.258$

17. Remberg. A.: Ruddat. A.: Braslavsky. S.: Gartner. W: Schath̀ner. K. Biochemistry 1998.37, 9983.

18. Lee, H. M: Kim. J: Kim. C. J: Kim. K. S. J. Chem. Phys. 2002. 116,6549 .

19. (a) Baik J.: Kim. J.: Kim. K. S. J. Chem. Phs. 1999, 110. 9116. (b) Majundar. D.: Kim. J. J. Chen. Phns. 2000. H2. 101. (c)
Majumdar. D.: Kim. K. S. J. Chent. Phrs 2000. 113. 5259. (d) Lee. H. M.: Kim. K. S. J. Chem. Phws 2001. Ht. 461.

20. (a) Kiml. C. J. Bull Korean Chent Soc. 2002. 23. 330. (b) Hong. S. Y.: Marynick, D. S. Macromolecules 1992, 25. 3591.

21. Ridlev, J.; Zemer. M. C. Theor: Chim Acta 1973. 32, 111

22. Zerner. M. C.; Loew. G. H; Kirchner. R. F.: Mueller-Westerhoff, U. T. J. Ant Chem. Soc. 1980. 102.589.

23. Frisch. M. T.: Truchs. G. W.: Schlegel. H. B.: Scuseria. G. E.: Robb. M. A.: Cheeseman. J. R.: Montgomery. J. A.. Jr: Vrevent. T.: Kudin, K. N.: Burant, J. C.: Millam, J. M.; Iyengar. S. S.; Tomasi, J.; Barone, V.: Mennueci. B.: Cossi. M.: Sealmani, G: Rega. N.: Petersson. G. A.; Nakatsuji, H.; Hada. M.: Ehara. M: Toyota. K.: Fukuda. R.: Hasegawa. J.: Ishida. M.: Nakajima. T.: Honda. Y.: Kitao. O.: Nakai. H.: Klene. M.: Li. X.: Knox. T. E.: Hratchian. H. P.: Cross. I. B.: Bakker1. V.: Adamo. C.: Taramillo. J; Gomperts. R.: Stratmann. R. E; Yazyev, O; Austin. A. J: Cammi. R.: Pomelli, C.; Ochterski, J. W: Avala, P. Y: Morokuma. K: Voth. G. A.: Salvador, P.: Dannenberg, J. J.: Zakrzewski. V. G: Dapprich. S.: Daniels. A. D.: Strain. M. C.: Farkas. O.: Malick. D. K.: Rabuck. A. D.: Raghavachari. K.: Foresmant. J. B.: Ottiz. J. V.: Cui. Q: Baboul. A. G.: Clifford. S.: Cioslowski. J.: Stefanov. B. B.; Liu. G; Liashenko, A.; Piskorz, P; Komaromi. I; Martin. R L.; Fox, D. J: Keith, T; Al-Laham, M. A.: Peng. C. Y: Nanayakkara, A.; Challacombe, M: Gill. P. M. W: Jolnson. B: Chen1. W.: Wong. M. W.: Gonzalez. C.: Pople. T. A. Ganssiam 03. revision B.05: Gaussiant. Ince: Wallingford. CT. 2003.

24. Gervasio. L.: Gardini. M.: Salvi. R.: Schettino. V. J. Phws. Chen. A 1998. 102. 2131.

25. Boruck, B.: van Stetten, D.; Seibeck, S.: Lamparter, T.; Michael. N.: Mroginsk. M. A.; Otto. H.: Murgida, D. H.; Hevn, M. P: Hidebrandt. P. J. Biol Chem. 2005. 280.34358.

26. Mora. M. E.: Bar. S. E.: Awruch. J.: Delfino. J. M. Bioorganic \& led Chem. 2003. 11. 4661 .

27. Koglin, M.: Behrends. S. Biochem. Pharm. 2002. 6f, 109

28. (a) Belletete. M: Mazerolle, L.; Desrosiers, N.: Leclere. M; Durocher. G. Macromolecules 1995, 28,8587. (b) Dicesare. N.; Belletete. M.: Leclere. M.: Durcher. G. J. Mol Snict. (Thechent) 1999. 467. 259. (c) Dicesare. N.: Belletete. M: Raymond. F: Leclere. M.: Durocher G. J. Phws. Chen. 1997. A101. 776. (d) Dicesare, N.: Belletete. M; Leclere, M.: Durocher, G. J. Plns. Chem $1998,4102,5142$

29. Kneip, C.: Hildebrandt. P.; Schlamann. W.: Nemeth, K.: Mark, F: Schaftiner. K. Chent. Phos Lett 1999. 311. 479.

30. Dabbagh. H. A.: Chemahini. A. R. N.: Madaresi-Alam. A. R. M. Bull. Korem Chent Soc. 2005. 26. 1229.

31. Lee. M. J.: Kim. D. H. Bull. Korean Chem Soc. 2006. 27.39

32. (a) Staub. J. M.: Deng, X.W. Photochem. Photobiol. 1996. 64. 897. (b) Smith. H. Amu. Rev. Plant. Phusiol Mfol Biol 1995. 167.330. (c) Schmidt. P.: Westphal. U. H.: Worm. K.: Braslavshy. S. E.: Gartner. W.: Schaftner. K. J. Photochem. Photobiol. B: Biolog: 1996. 34. 73 .

33. (a) Buchler. R.: Hermann. G.: Lap, D. V.: Rentsch. S. Chem. Phus Lett. 1995, 233, 514. (b) Tokutomi, S.: Sugimoto. T; Mimuro. M Phothochem. Photobiol 1992, $56,542$.

34. Jan1g. S.: Jin. S. I.: Park. C. R. Bull. Korem Chent Soc. 2007. $28(12) 2343$. 